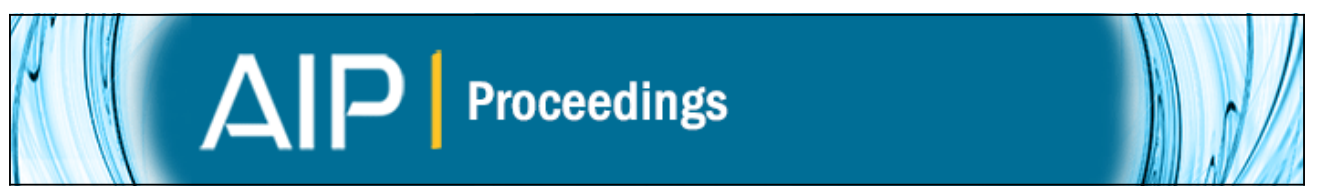

\title{
Mechanistic Study of Plasma Damage of Low k Dielectric Surfaces
}

Junjing Bao, Hualiang Shi, Junjun Liu, Huai Huang, P. S. Ho, M. D. Goodner, M. Moinpour, and G. M. Kloster

Citation: AIP Conference Proceedings 945, 125 (2007); doi: 10.1063/1.2815773

View online: http://dx.doi.org/10.1063/1.2815773

View Table of Contents: http://scitation.aip.org/content/aip/proceeding/aipcp/945?ver=pdfcov Published by the AIP Publishing

\section{Articles you may be interested in}

Sequential lateral solidification of silicon thin films on low-k dielectrics for low temperature integration

Appl. Phys. Lett. 105, 242904 (2014); 10.1063/1.4904938

Mechanistic study of plasma damage of low $\mathrm{k}$ dielectric surfaces

J. Vac. Sci. Technol. B 26, 219 (2008); 10.1116/1.2834562

Dielectric/metal sidewall diffusion barrier for $\mathrm{Cu} /$ porous ultralow-k interconnect technology Appl. Phys. Lett. 84, 2442 (2004); 10.1063/1.1695205

Plasma-enhanced chemical vapor deposition of low-k dielectric films using methylsilane, dimethylsilane, and trimethylsilane precursors

J. Vac. Sci. Technol. A 21, 388 (2003); 10.1116/1.1539086

Plasma enhanced chemical vapor deposited SiCOH dielectrics: from low-k to extreme low-k interconnect materials

J. Appl. Phys. 93, 1785 (2003); 10.1063/1.1534628 


\title{
Mechanistic Study of Plasma Damage of Low k Dielectric Surfaces
}

\author{
Junjing Bao, Hualiang Shi, Junjun Liu*, Huai Huang and P.S. Ho \\ M.D. Goodner** ${ }^{* *}$, Moinpour ${ }^{* *}$ and G.M. Kloster ${ }^{* * *}$ \\ Materials Laboratory for Interconnect and Packaging \\ The University of Texas at Austin, Austin, TX 78712-1063 \\ *Tokyo Electron U.S. Holdings Inc., 2400 Grove Blvd., Mail stop C310, Austin, TX 78741 \\ Intel Corporation, Logic Technology Development, Hillsboro, OR 97124
}

\begin{abstract}
Plasma damage to low $\mathrm{k}$ dielectric materials was investigated from a mechanistic point of view. Low $\mathrm{k}$ dielectric films were treated by plasma $\mathrm{Ar}, \mathrm{O}_{2}, \mathrm{~N}_{2} / \mathrm{H}_{2}, \mathrm{~N}_{2}$ and $\mathrm{H}_{2}$ in a standard RIE chamber and the damage was characterized by Angle Resolved X-ray Photoelectron Spectroscopy (ARXPS), X-Ray Reflectivity (XRR), Fourier Transform Infrared Spectroscopy (FTIR) and Contact Angle measurements. Both carbon depletion and surface densification were observed on the top surface of damaged low $\mathrm{k}$ materials while the bulk remained largely unaffected. Plasma damage was found to be a complicated phenomenon involving both chemical and physical effects, depending on chemical reactivity and the energy and mass of the plasma species. A downstream hybrid plasma source with separate ions and atomic radicals was employed to study their respective roles in the plasma damage process. Ions were found to play a more important role in the plasma damage process. The dielectric constant of low k materials can increase up to $20 \%$ due to plasma damage and we attributed this to the removal of the methyl group making the low $\mathrm{k}$ surface hydrophilic. Annealing was generally effective in mitigating moisture uptake to restore the $\mathrm{k}$ value but the recovery was less complete for higher energy plasmas. Quantum chemistry calculation confirmed that physisorbed water in low $\mathrm{k}$ materials induces the largest increase of dipole moments in comparison with changes of surface bonding configurations, and is primarily responsible for the dielectric constant increase.
\end{abstract}

Keywords: Low k; Surface; Chemical and physical effects; Hybrid source; Plasma damage; Mechanism; Hydrophobic; Recovery

PACS: $77.55 .+$ f Dielectric thin films

\section{INTRODUCTION}

As silicon technology advances beyond the $45 \mathrm{~nm}$ node, ultra low $\mathrm{k}$ (ULK) dielectrics with porosity will be required for $\mathrm{Cu}$ interconnects [1-2]. The mechanical and electrical properties of low $\mathrm{k}$ dielectrics tend to degrade when they are exposed to plasma processes during fabrication. The degradation will affect not only the chip performance but also the circuit reliability and will be worsened with the incorporation of porosity in the ULK dielectrics [3]. Since plasma processing is commonly used for etching, stripping and cleaning, this problem raises serious challenges to low $\mathrm{k}$ integration and has stimulated extensive interests recently in the study of plasma damage of ULK dielectrics [4].

Several recent papers have reported results from plasma damage studies on blanket and patterned low $\mathrm{k}$ dielectric materials [5-8]. These studies have largely focused on 
two aspects of plasma damage to low $\mathrm{k}$ dielectric materials. The first is to search for effective plasmas to minimize the damage, such as the use of $\mathrm{He}$ or $\mathrm{NH}_{3}$ plasma in the striping process [9-10], and the other is to recover the dielectric loss, with $\mathrm{CH}_{4}$ plasma or silylation agents [11-14].

Current organosilicate low $\mathrm{k}$ materials are based on methylsilsesquioxane (MSQ) formed with Si-O-Si backbone bonds and incorporating methyl groups and porosity to reduce the dielectric constant. The plasma damage of such materials will in general be a complex phenomenon depending on the process history and involving both chemical and physical interactions between the plasma species and the material constituents. Cui et al. observed that film densification and material removal were two processes limiting the thickness reduction of the $\mathrm{SiCOH}$ low $\mathrm{k}$ film during plasma treatment ${ }^{10}$. Few of the other publications have discussed the mechanism how plasma interacts with low $\mathbf{k}$ dielectric surfaces leading to damage. This study investigates the mechanism of plasma damage to porous carbon-doped oxide (CDO) low k films. First the nature of damage by different plasma treatments including $\mathrm{H}_{2}, \mathrm{Ar}$ and $\mathrm{O}_{2}$ in a standard RIE chamber was analyzed using multiple analytical techniques including $\mathrm{x}$ ray photoemission spectroscopy (XPS), Fourier transform IR spectroscopy (FTIR) and $\mathrm{x}$-ray reflectivity (XRR). The results quantified the plasma effects on surface chemistry, composition, density and dielectric constant of the low $\mathrm{k}$ film and provided information to understand the chemical and physical effects from the plasma interaction with the low $\mathrm{k}$ materials. The damage mechanism was further examined using a downstream hybrid plasma source with a unique capability of separating ions from atomic radicals to investigate their respective roles in the damage process.

The dielectric constant of low $\mathrm{k}$ materials after plasma would generally increase depending on the specific plasma used. Reasons for dielectric constant increase are discussed and the effects for different plasmas are compared in this paper. Based on the observation of possible molecular interactions with plasma, quantum chemistry calculations are performed to examine their dipole contributions leading to the increase in the dielectric constant.

\section{EXPERIMENTAL DETAILS}

The pristine CDO films were deposited with about $25 \%$ porosity to yield a dielectric constant of 2.5 , film density of $1.25 \mathrm{~g} / \mathrm{cm}^{3}$ and refractive index at $633 \mathrm{~nm}$ of 1.33. Standard plasma processing was performed in an Oxford Plasmalab 80 Plus Reactive Ion Etching (RIE) chamber in a clean room. All the samples were processed at room temperature.

The downstream plasma studies were performed in an UHV system designed in our laboratory consisting of a plasma process chamber connected to an XPS analysis chamber via a loadlock as shown in Fig.1. Downstream plasma such as $\mathrm{NH}_{3}$ was generated by cracking $\mathrm{NH}_{3}$ gas molecules with electron cyclotron resonance (ECR) inside an Oxford Scientific mini atom/ion hybrid source. The source was mounted on the plasma process chamber and aimed at the sample surface at an angle of about 40 degrees from a distance of about $10 \mathrm{~cm}$. Fig. 2 is the schematic diagram of the plasma 
source. At the atom mode, the dielectric BN/Mo aperture can be rapidly charged with ions to filter out ions in the beam. In this way, ions in the beam can be differentially pumped away, and thus only neutral species can reach the center of the plasma chamber through the aperture. At the hybrid mode, a high voltage was applied to the Mo grid to accelerate ions and neutralize charge accumulation on the aperture. Ions up to $2.2 \mathrm{keV}$ energy can be added to the neutral species in the process chamber. In this paper, the term hybrid or plasma beam refers to a mixture of ions and neutral species, while the term radical beam refers to only the neutral species. The beam density at the sample surface was estimated to be of the order of $10^{12}$ atoms/ $\left(\mathrm{cm}^{2} \cdot \mathrm{s}\right)$ [15]. The plasma chamber pressure was typically maintained at 1.2 mtorr during processing. At any point during processing, the sample can be directly transferred from the plasma chamber to the analysis chamber for in-situ XPS analysis without exposing to air and contaminations. Samples were stored in a Labconco vacuum desiccator after experiments.

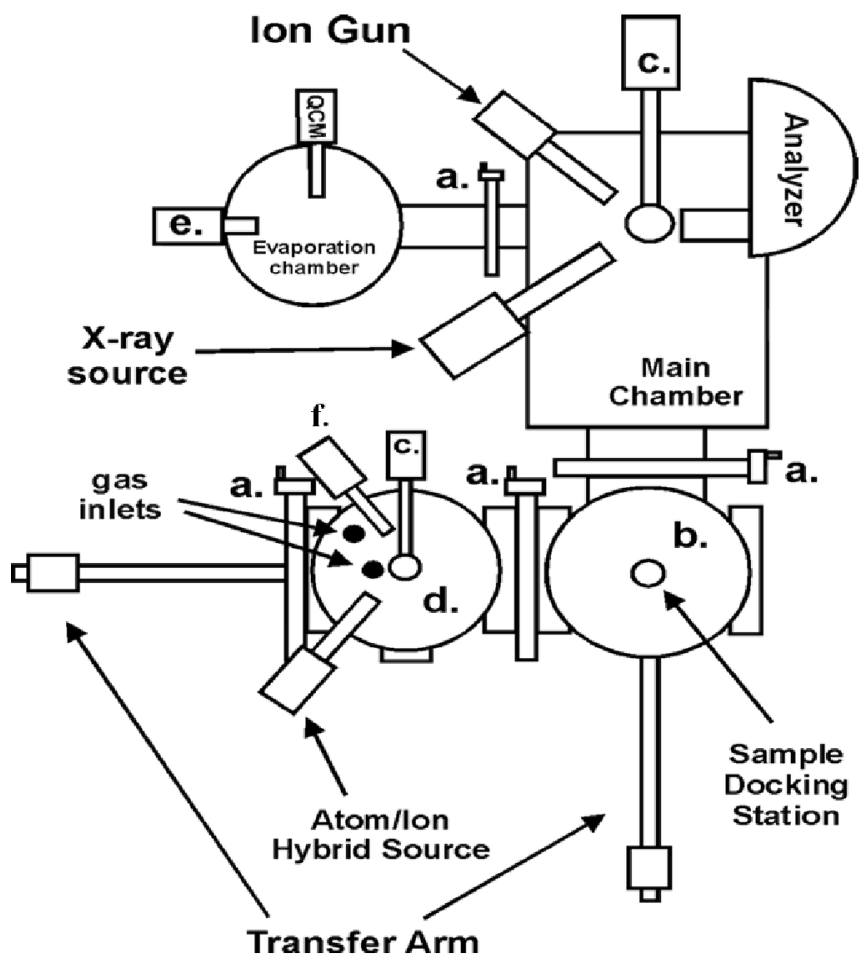

Figure 1. Schematic diagram of downstream plasma chamber connected to the insitu XPS analysis chamber. Samples can be transferred from the plasma chamber to the XPS chamber without breaking vacuum at any desired point of interest. 


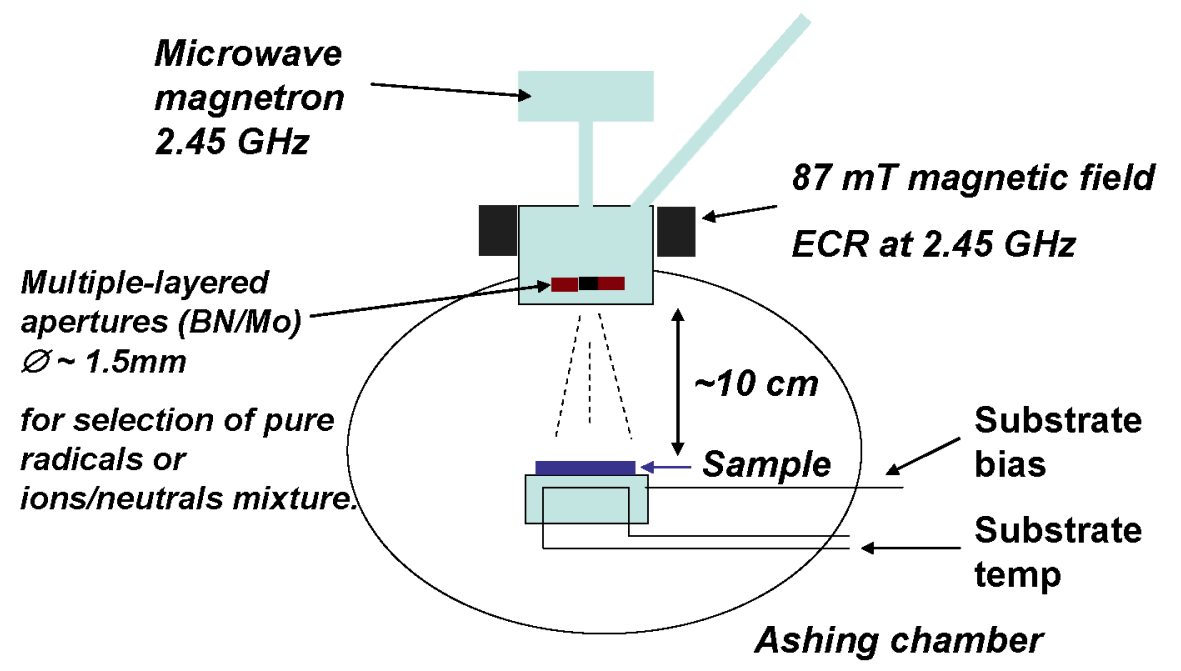

Figure 2. Schematic diagram of the hybrid source. Plasma was generated in a separated chamber aiming at the sample at an angle of $40^{\circ}$. During experiments, the substrate was rotated until the plasma beam became vertical to the sample substrate. Plasma energy ranged from 0 to $2.2 \mathrm{keV}$.

The XPS experiment has been described in detail in previous papers [16-17]. The base pressure of the XPS UHV chamber typically reached $2 \times 10^{-9}$ torr. A nonmonochromatic Al k $\alpha$ x-ray source was used to generate photoelectrons which were analyzed using a Leybold hemisphere analyzer operating at $38.45 \mathrm{eV}$ pass energy. A linear background subtraction was used for the Cls spectra and the Shirley background subtraction was applied to other peaks. XPS depth profiling was performed after plasma treatment in a PHI 5700 XPS system equipped with dual $\mathrm{Mg}$ $\mathrm{X}$-ray source and monochromatic Al X-ray source. The photoelectrons emitting from the sample surface were detected at an exit angle of $45^{\circ}$. The Ar ion sputtering rate was calibrated to be $20 \mathrm{~nm} / \mathrm{min}$. for our CDO film.

The film thickness and the refractive index at $633 \mathrm{~nm}$ were measured with a J. A. Woollam VASE Spectroscopic Ellipsometer 2000. The water contact angle was measured using a CA100 Ramé-Hart goniometer. Chemical bond structures were investigated with Magna 560 FTIR Spectrometer with an attenuated total reflectance (ATR) attachment. FTIR in the transmission mode studied the bond structures in the bulk of the film while in the ATR mode, it studied the bond structure of the sample surface in contact with the ATR crystal. The surface roughness after plasma treatment was extracted from a $1 \times 1 \mu \mathrm{m}$ Atomic Force Microscopy image. The film density was determined by measuring $x$-ray reflectivity using a X'Pert MRD system. The dielectric constant at $1 \mathrm{MHz}$ was obtained by measuring a metal-insulator-semiconductor structure using a HP 4194A Impedance Phase Analyzer. The quantum chemistry calculation was performed using the Gaussian 03 software developed by Gaussian Inc., was used to compare the dipole contribution from various molecular structures to the dielectric constant of the low $\mathrm{k}$ film [18]. 


\section{RESULTS AND DISCUSSION}

\section{A: Plasma damage in the RIE chamber}

Pristine CDO films were treated by different plasmas in the Oxford RIE chamber under an identical condition of $30 \mathrm{sccm}, 30 \mathrm{mtorr}$, and $150 \mathrm{w}$ for $20 \mathrm{~min}$. The plasma damage was measured by XPS at a take-off angle of $30^{\circ}$ to examine the changes in the elemental compositions of the low $\mathrm{k}$ surface. The relation between photoelectron sampling depth and the take-off angle can be expressed as $d \sim 3 \lambda \sin \theta$ $(\lambda \sim 2-4 \mathrm{~nm})$ [19]. At a take-off angle of $30^{\circ}$, the photoelectrons escaped from a sampling depth of about $5 \mathrm{~nm}$ beneath the damaged surface. The XPS results revealed that the surface carbon concentration was reduced due to the loss of the methyl group as a result of plasma interaction with the low $\mathrm{k}$ dielectric surface. As summarized in Table I, the loss of the surface carbon concentration was the highest by the $\mathrm{H}_{2}$ plasma, reducing it from the pristine surface of $12.6 \%$ to $1.25 \%$. Thus the $\mathrm{H}_{2}$ plasma was the most effective in removing carbon, i.e. methyl groups on the low $\mathrm{k}$ surface since it is the lightest and most chemically reactive. For the other plasmas, $\mathrm{N}_{2}, \mathrm{O}_{2}$, and $\mathrm{Ar}$, the methyl loss was somewhat less, yielding a surface carbon concentration ranging from $1.93 \%$ to $2.41 \%$. Accompanying the surface carbon loss, a shift in the binding energy of the C1s peak from the pristine $283.54 \mathrm{eV}$ was observed, which can be attributed to the incorporation of electronegative elements into low k dielectrics. Since the more electronegative the element a larger shift would be induced, the biggest chemical shift of $0.9 \mathrm{eV}$ was found to be caused by the $\mathrm{O}_{2}$ plasma, as expected. Interestingly, a change of the bonding configuration due to physical bombardment of heavy atoms/molecules can also contribute to the chemical shift, such as the $0.5 \mathrm{eV}$ increase observed after Ar plasma treatment. In a previous study, when physical bombardment induced amorphous or unbonded carbon atoms in the film, a shift of $\sim 1 \mathrm{eV}$ of the $\mathrm{Cls}$ peak was observed [20].

The plasma damage was examined by FTIR and by measuring the water contact angle. The FTIR spectra of the low $\mathrm{k}$ surface after various plasma treatments are shown in Figure 3. All the low k surfaces show a reduction in the $\mathrm{Si}_{-} \mathrm{CH}_{3}$ peak at 1274 $\mathrm{cm}^{-1}$ due to the loss of the methyl group. This is accompanied by an increase of the Si-OH and $\mathrm{H}_{2} \mathrm{O}$ peak between 3200 and $3600 \mathrm{~cm}^{-1}$, changing the surface to be hydrophilic. This result is consistent with the water contact angle measurements, which indicate a decrease of the contact angle after all plasma treatments. The amount of Si-OH after Ar plasma is the second smallest while the surface after $\mathrm{O}_{2}$ plasma is the most hydrophilic, reducing its water contact angle to as low as $50^{\circ}$. In contrast, the $\mathrm{H}_{2}$ plasma tends to transform $\mathrm{Si}_{-} \mathrm{CH}_{3}$ into $\mathrm{Si}-\mathrm{H}$, making the surface the least hydrophilic. In general, the low k surface after plasma treatment will take up more moisture to cause an increase in the dielectric constant. This effect is discussed in a later section. 
Table 1. Carbon composition and dielectric polarization of low $\mathbf{k}$ films after plasma damage. Samples were treated by $\mathrm{H}_{2}, \mathrm{~N}_{2}, \mathrm{~N}_{2} / \mathrm{H}_{2}, \mathrm{O}_{2}, \mathrm{Ar}$ plasmas at $30 \mathrm{sccm}, 30 \mathrm{mtorr}$ for $20 \mathrm{~min}$. in an Oxford RIE chamber.

\begin{tabular}{|c|c|c|c|}
\hline & $\begin{array}{c}\text { Carbon Peak } \\
\text { Position (eV) }\end{array}$ & $\begin{array}{c}\text { Surface carbon } \\
\text { concentration }\end{array}$ & $\begin{array}{c}\text { Water } \\
\text { Contact Angle ( }{ }^{\circ}\end{array}$ \\
\hline Pristine & 283.54 & $12.6 \%$ & 93 \\
\hline $\mathrm{H}_{2}$ & 283.61 & $1.25 \%$ & 85 \\
\hline $\mathrm{N}_{2}$ & 284.22 & $1.93 \%$ & 58 \\
\hline $\mathrm{N}_{2} / \mathrm{H}_{2}$ & 284.37 & $2.08 \%$ & 60 \\
\hline $\mathrm{O}_{2}$ & 284.42 & $2.41 \%$ & 50 \\
\hline $\mathrm{Ar}$ & 284.09 & $2.22 \%$ & 62 \\
\hline
\end{tabular}

Interestingly, after $\mathrm{H}_{2}$ plasma, the Si-O-Si peak between 950 and $1250 \mathrm{~cm}^{-1}$ almost did not change at all, but the same peak was significantly modified by Ar plasma. Since this peak is associated with the Si-O-Si backbone structure of the low $\mathrm{k}$ materials, the result indicates a change of the structural bonding due to the physical bombardment of the plasma and the effect is higher for Ar than $\mathrm{H}_{2}$. Nitrogen- or oxygen-containing plasmas also caused some modifications of Si-O-Si backbone structures. In addition, it is worth noting that nitrogen-containing plasmas promotes the appearance of a wide peak between 1590 and $1625 \mathrm{~cm}^{-1}$ that is associated with the $\mathrm{C}=\mathrm{C}$ bonds [21]. This can be attributed to the interaction between $\mathrm{N}$ or $\mathrm{NH}_{\mathrm{x}}$ in the plasma with $\mathrm{H}$ in the methyl group, providing unsaturated bonds to form $\mathrm{C}$ double bonds.

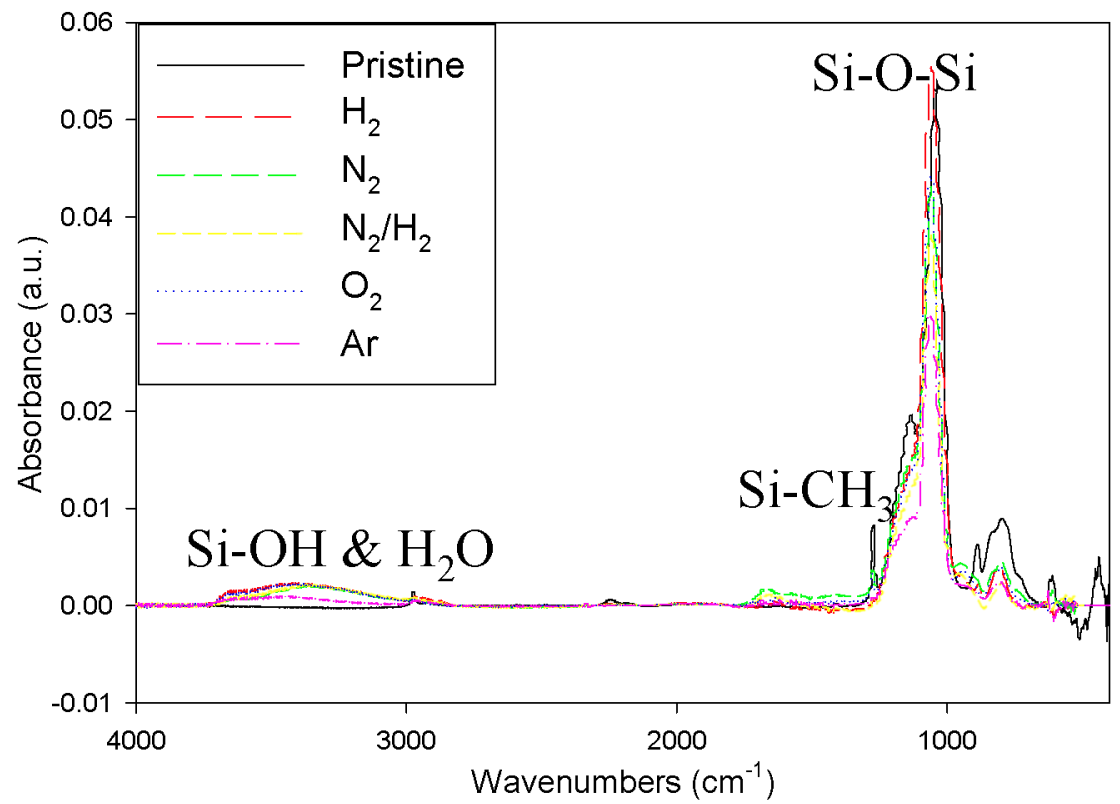




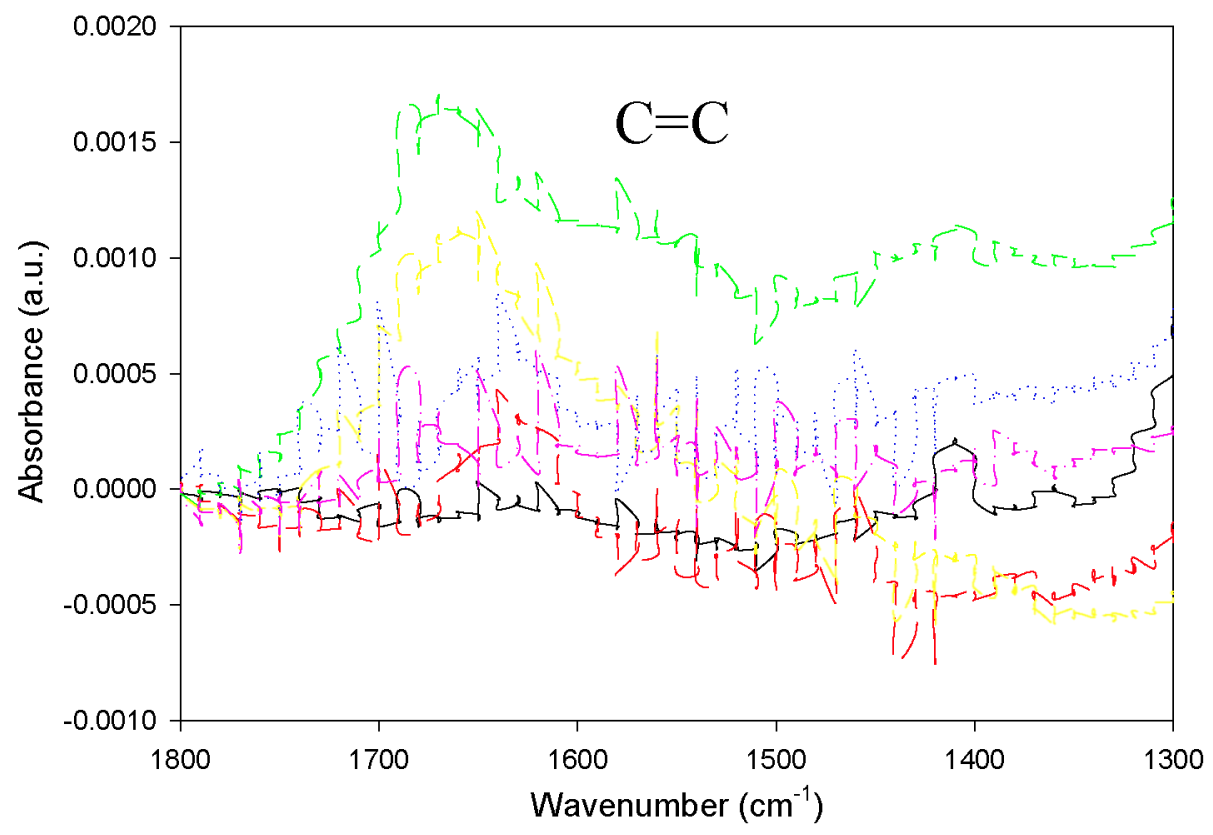

Figure 3. FTIR spectra of low $\mathrm{k}$ film after $\mathrm{H}_{2}, \mathrm{~N}_{2}, \mathrm{~N}_{2} / \mathrm{H}_{2}, \mathrm{O}_{2}$, Ar plasma treatments at $30 \mathrm{sccm}, 30 \mathrm{mtorr}$ and $150 \mathrm{w}$ for $20 \mathrm{~min}$. in an Oxford RIE chamber.

To delineate the chemical and physical nature of the plasma damage, we performed $\mathrm{x}$-ray reflectivity (XRR) measurements to investigate the density and thickness of the damaged surface after plasma treatments. The XRR technique uses a highly collimated and monochromatic x-ray beam to probe the sample surface at a low angle $\left(0^{0}-5^{0}\right)$ and the reflected beam intensity is analyzed. In a typical XRR curve, the critical angle provides a measure of the film density; the period of fringes measures the film thickness; and the slope measures the roughness [22]. In our studies, XRR curves were fit with X'Pert software to deduce the film density after different plasma treatments in the Oxford RIE chamber. An analysis of the XRR data revealed the formation of a thin but dense layer of $\sim 10 \mathrm{~nm}$ on the damaged CDO film surface while the bulk remained unaltered. This layer had a gradient in the density distribution with the highest density on the top. Figure 4 shows the averaged density of the damaged layer by different plasma species. Overall, the density of the damaged layer depended on the mass of the plasma radicals, increasing from $1.79 \mathrm{~g} / \mathrm{cm}^{3}$ for $\mathrm{H}_{2}$ plasma to $2.16 \mathrm{~g} / \mathrm{cm}^{3}$ for $\mathrm{Ar}$ plasma. The trend is consistent with a physical effect due to bombardment by atoms/molecules and is most effective for the heaviest Ar plasma for densification of the low $\mathrm{k}$ surface. 

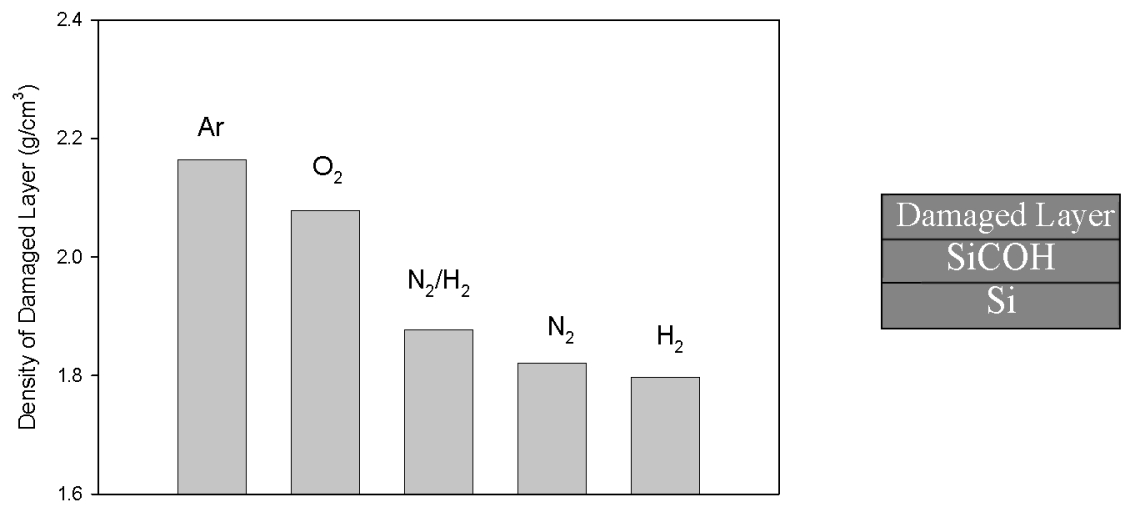

Figure 4. Density measurements of the plasma damage region. Samples were treated by $\mathrm{H}_{2}, \mathrm{~N}_{2}, \mathrm{~N}_{2} / \mathrm{H}_{2}, \mathrm{O}_{2}$, Ar plasmas at $30 \mathrm{secm}, 30$ mtorr and $150 \mathrm{w}$ for $20 \mathrm{~min}$. in an Oxford RIE chamber.

Experiments were also performed for different plasma treatments at the energies of $50 \mathrm{eV}$ and $200 \mathrm{eV}$ while keeping all the other process parameters the same. The normalized thickness changes are plotted in Figure 5. At a low energy of $50 \mathrm{eV}$, the plasma process was dominated by chemical reactions and the low $\mathrm{k}$ film was etched fastest by $\mathrm{H}_{2}$ plasma with a thickness reduction of $\sim 14 \%$. In contrast, at $200 \mathrm{eV}$, the low $\mathrm{k}$ film was etched fastest by Ar plasma with a thickness reduction of $\sim 56 \%$ primarily by physical bombardment. This result together with the XRR data on surface densification show that physical effects are dominated by plasmas with heavy molecular weights at high energy and dose, e.g. Ar and $\mathrm{O}_{2}$, while chemical effects are dominated by plasmas with light molecular weights at low energy and dose, e.g. $\mathrm{H}_{2}$ and $\mathrm{N}_{2}$.

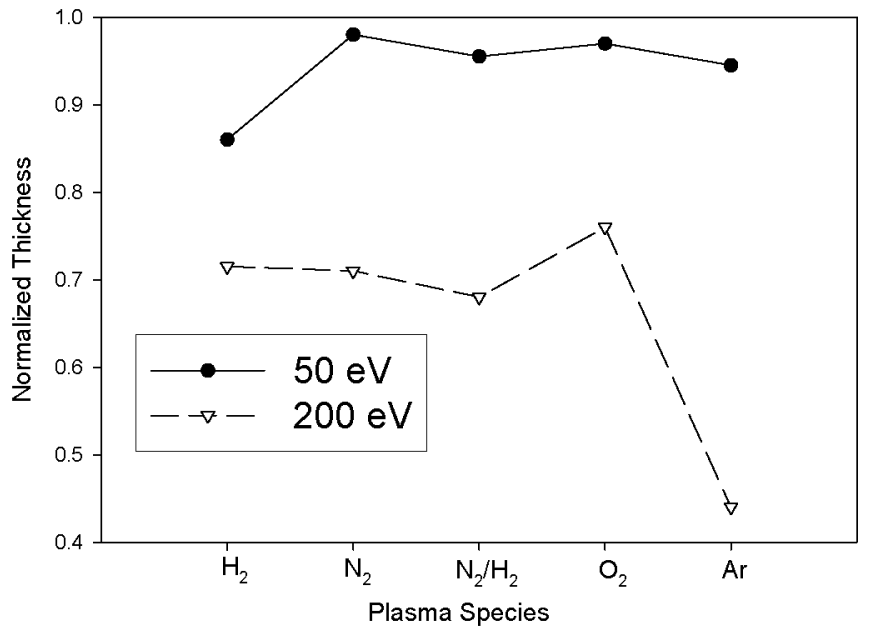

Figure 5. Normalized thicknesses of low k film after plasma treatments. Samples were treated by different plasmas at the energy of $50 \mathrm{eV}$ and $200 \mathrm{eV}$ in an Oxford RIE chamber. 


\section{B: Downstream Plasma Damage}

Plasma damage of the low $\mathrm{k}$ surface was further studied using the downstream hybrid source. This source can provide a proper mix of ions and neutral species to study their respective roles in plasma damage. In addition, the process parameters such as plasma energy, plasma species, processing pressure and substrate temperature can be individually controlled. Three types of plasmas, $\mathrm{NH}_{3}, \mathrm{Ar}$ and $\mathrm{He}$, were chosen to study the chemical and physical effects of plasma damage on low k dielectrics.

In Table II, we summarized the surface roughness, FTIR/ATR bond intensity ratios, water contact angle and dielectric constants of $\mathrm{CDO}$ films after downstream $\mathrm{NH}_{3}, \mathrm{Ar}$ and $\mathrm{He}$ plasmas treatments. At $100 \mathrm{eV}$, the low energy plasma treatment had negligible effects on surface roughness and bulk $\mathrm{Si}_{-} \mathrm{CH}_{3}$ concentrations as seen from the FTIR $\mathrm{Si}-\mathrm{CH}_{3} / \mathrm{Si}-\mathrm{O}-\mathrm{Si}$ ratios. As analyzed by $\mathrm{ATR}$, the $\mathrm{Si}-\mathrm{CH}_{3}$ bonds on the low $\mathrm{k}$ surface were all reduced by downstream plasmas, leading to a reduction in the water contact angle. The water contact angle and thus the moisture uptake were the most affected by $\mathrm{NH}_{3}$ plasma. The reason for this result will be discussed in the next paragraph. Interestingly, the $\mathrm{Si}-\mathrm{CH}_{3}$ bonds on the low k surface were most severely broken by $\mathrm{Ar}$ plasma as reflected by its ATR ratio to the $\mathrm{Si}-\mathrm{O}-\mathrm{Si}$ bonds, which was reduced from 0.155 to 0.127 . However, the water contact angle and the $\mathrm{Si}-\mathrm{OH}$ concentration after Ar plasma were smaller than that after He plasma treatment. This suggests some surface densification due to Ar bombardment blocking moisture penetration. This densification can be related to the modification of pore density and pore interconnection in the top surface. It was reported that the low $\mathrm{k}$ material after $\mathrm{Ar}$ plasma showed a $4.4 \%$ reduction in open porosity and a $2.2 \%$ reduction in the total porosity compared with that after $\mathrm{O}_{2}$ plasma. This can result in the delayed absorption or diffusion of moisture in the low $\mathrm{k}$ film [23]. Compared with the dielectric constant of 2.5 of the pristine material, the dielectric constant after plasma damage increased to 2.90-3.0, indicating considerable damage and moisture penetration in the low $\mathrm{k}$ film.

Table 2. Property of the low $\mathrm{k}$ film after $100 \mathrm{eV} \mathrm{NH}, \mathrm{Ar}$ and $\mathrm{He}$ downstream plasma treatments at 1 mtorr for $15 \mathrm{~min}$.

\begin{tabular}{|c|c|c|c|c|}
\hline Sample condition & Pristine sample & $100 \mathrm{eV}$ hybrid He & $100 \mathrm{eV}$ hybrid $\mathrm{NH}_{3}$ & $100 \mathrm{eV}$ hybrid Ar \\
\hline Roughness (nm) & $0.327 \pm 0.021$ & $0.506 \pm 0.081$ & $0.320 \pm 0.021$ & $0.296 \pm 0.044$ \\
\hline $\mathrm{ATR} \mathrm{Si-CH} 3 / \mathrm{Si}-\mathrm{O}-\mathrm{Si}$ & 0.155 & 0.154 & 0.135 & 0.127 \\
\hline FTIR Si-CH $3 / \mathrm{Si}-\mathrm{O}-\mathrm{Si}$ & 0.018 & 0.020 & 0.016 & 0.016 \\
\hline FTIR Si-OH/Si-O-Si & 0.022 & 0.055 & 0.077 & 0.037 \\
\hline Contact Angle $\left({ }^{0}\right)$ & 93 & 86 & 46 & 63 \\
\hline Dielectric Constant & $2.50 \pm 0.03$ & $2.91 \pm 0.01$ & $2.91 \pm 0.08$ & $3.00 \pm 0.07$ \\
\hline
\end{tabular}

Compared with $\mathrm{Ar}$ and $\mathrm{O}_{2}$ plasmas, the $\mathrm{NH}_{3}$ plasma seems to cause less damage to low $\mathrm{k}$ materials, especially when used in the downstream mode. This suggests the possibility of using downstream $\mathrm{NH}_{3}$ plasma in the photoresist stripping process [24]. The variation in the surface composition during $\mathrm{NH}_{3}$ plasma treatment is shown in Figure 6 where the carbon concentration was found to decrease due to the removal of 
methyl groups which were replaced by the $\mathrm{NH}_{\mathrm{x}}$ groups during plasma treatment. As expected, the binding energy of the carbon increased due to the incorporation of the electronegative nitrogen. The polar groups of $\mathrm{NH}_{\mathrm{x}}$ made the surface hydrophilic leading to moisture uptake and a decrease in the water contact angle as observed. Although the downstream plasma reaching the substrate was very weak, a gradient in the carbon depletion and a nitrogen penetration layer were found by XPS depth profiling as shown in Fig. 7. Based on an Ar sputtering rate of $20 \mathrm{~nm} / \mathrm{min}$., the range of carbon depletion and nitrogen penetration was estimated to be about $20 \mathrm{~nm}$. Beyond this range, the carbon concentration became level with no nitrogen in presence, indicating that the damage caused by downstream $\mathrm{NH}_{3}$ plasma treatment was restricted to near the sample surface with little effect on the bulk chemistry.
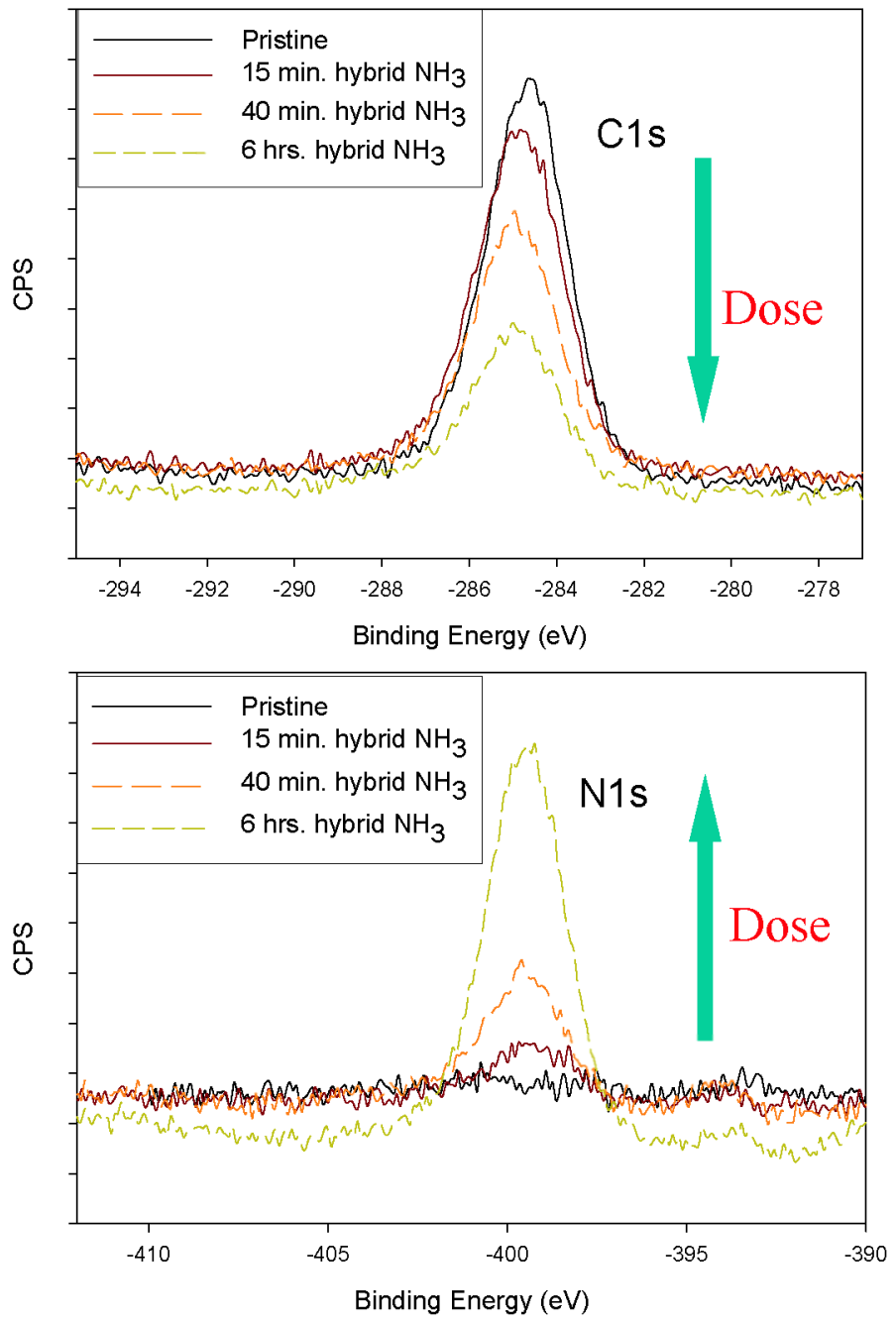

Figure 6. Evolution of the surface elemental concentration with plasma dosage. Samples were treated by downstream $\mathrm{NH}_{3}$ plasma for 15 min., 40 min. and 6 hours respectively. 


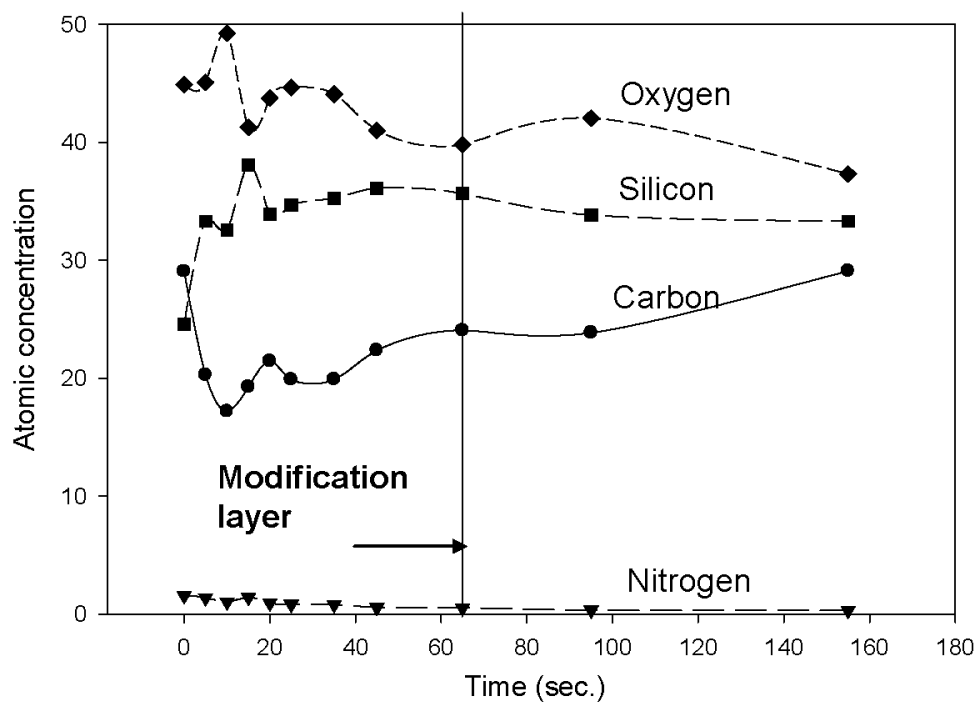

Figure 7. XPS depth profiling of the low $\mathrm{k}$ dielectric damaged by a 400 $\mathrm{eV}$ downstream $\mathrm{NH}_{3}$ plasma at 1 mtorr for 6 hours.

Differential FTIR was used to probe the change of bonding characteristics by downstream $\mathrm{NH}_{3}$ plasma. As shown in Figure 8a, the differential spectra obtained by subtracting FTIR spectra of the pristine sample show an increase in Si-OH between 3200 and $3600 \mathrm{~cm}^{-1}$. This indicates that $\mathrm{NH}_{3}$ plasma transformed the hydrophobic pristine film to become hydrophilic. In Fig. $8 b$, the differential spectra reveal a decrease of $\mathrm{Si}_{-} \mathrm{CH}_{3}$ at $1274 \mathrm{~cm}^{-1}$ with corresponding changes in the Si-O-Si bonds. In general, the Si-O-Si bonding configurations in MSQ low $\mathrm{k}$ dielectrics can be deconvoluted into three types: the network structure with a bonding angle of $140^{\circ}$ at around $1063 \mathrm{~cm}^{-1}$, the suboxide structure of less than $140^{\circ}$ at around $1023 \mathrm{~cm}^{-1}$ and the cage structure of $150^{\circ}$ at around $1135 \mathrm{~cm}^{-1}$ [25]. The differential FTIR spectra in Fig. $8 \mathrm{~b}$ show an increase of the suboxide bonds with corresponding decreases in the cage and network structures. This indicates that plasma damage not only affects the surface bonding but also induces structural disorders into the Si-O-Si backbone bonds. 

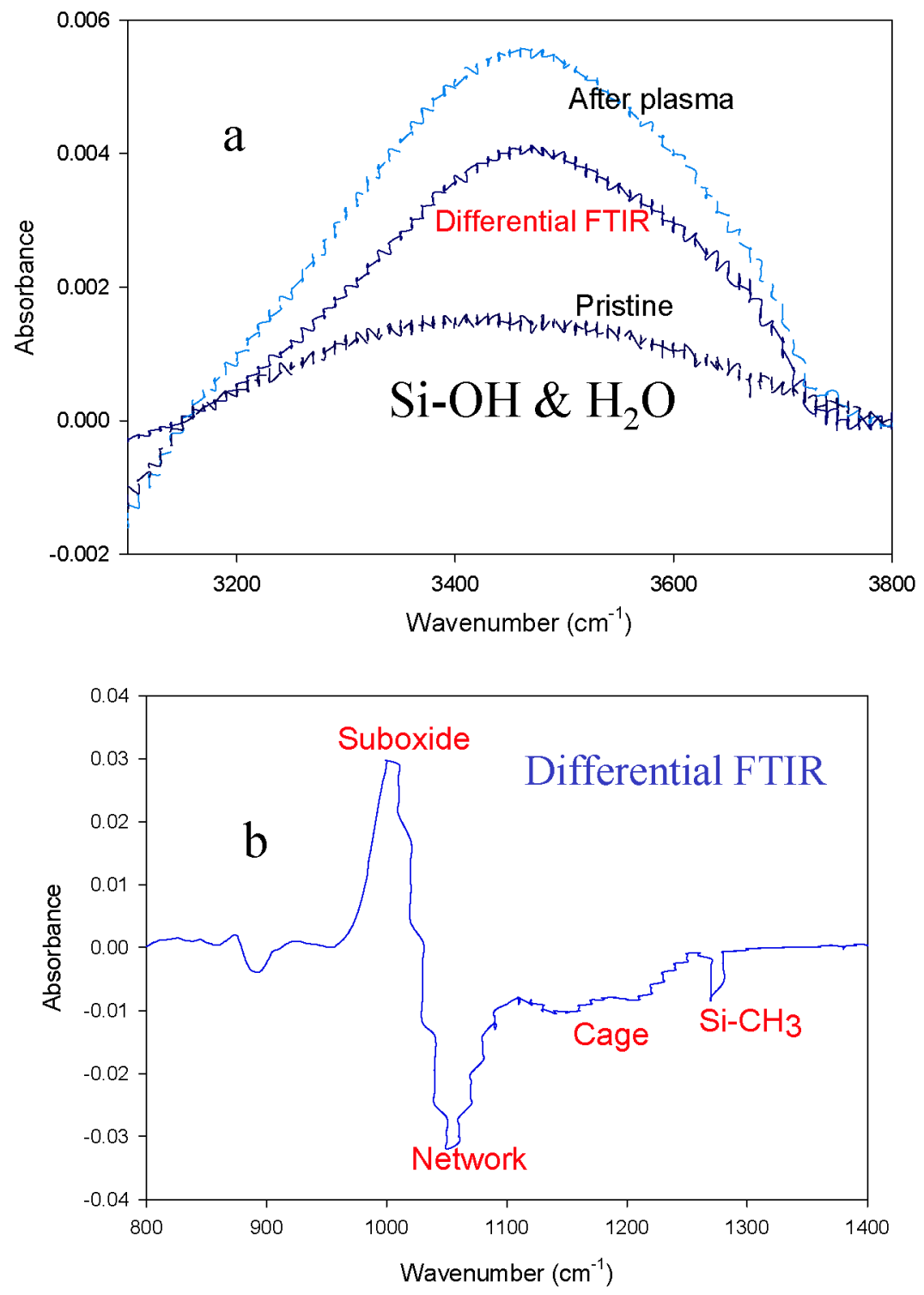

Figure 8. (a) FTIR and differential FTIR spectra show the increase of $\mathrm{Si}-\mathrm{OH}$ and moisture uptake in the low $\mathrm{k}$ sample after $\mathrm{NH}_{3}$ plasma. (b) Differential FTIR spectra show changes of Si-O-Si (suboxide, network and cage) and $\mathrm{Si}-\mathrm{CH}_{3}$ after $\mathrm{NH}_{3}$ plasma treatment. Samples were treated by $400 \mathrm{eV} \mathrm{NH} \mathrm{N}_{3}$ plasma at $1 \mathrm{mtorr}$ for $15 \mathrm{~min}$. 
The results in Fig. 9 show that with the same plasma dosage, the reactive $\mathrm{NH}_{3}$ beam induced more carbon loss than the inert He. In addition, hybrid beams caused significantly more carbon loss than radical beams due to the presence of ions in hybrid beams. The ions at metastable states accelerated the loss of the methyl groups because the energetics of the reaction changes the Gibbs free energy to be more negative. This helps to overcome the reaction barrier and facilitate the generation of reaction byproducts.

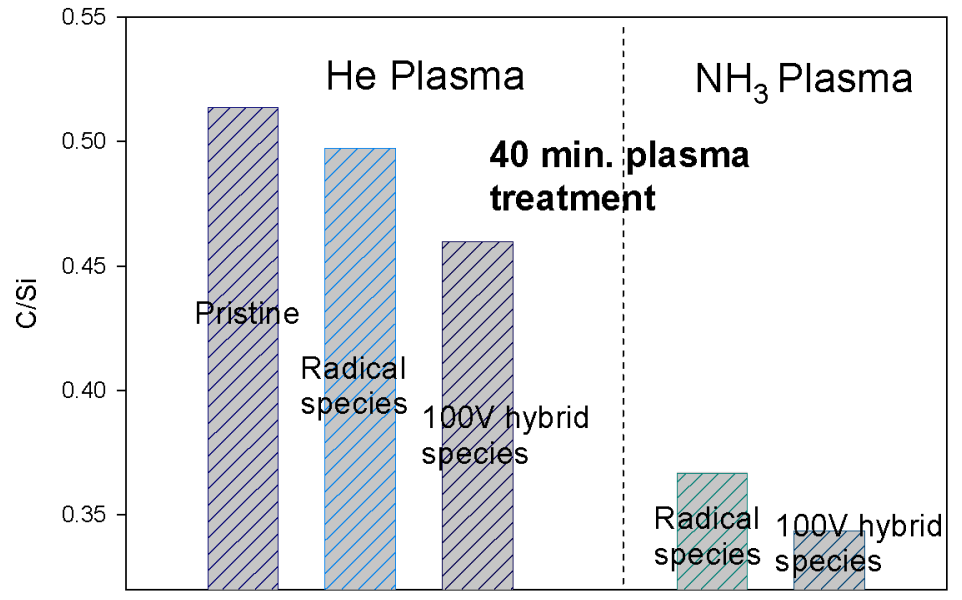

Figure 9. Ratios of $\mathrm{C} / \mathrm{Si}$ within $5 \mathrm{~nm}$ at top of the low $\mathrm{k}$ film after $\mathrm{He}$ and $\mathrm{NH}_{3}$ plasma treatment at 1 mtorr for 40 min.. Hybrid species include both ions and neutrals where the ion energy was $100 \mathrm{eV}$ and the radical species consists of neutrals only.

\section{C: Moisture uptake and dielectric constant increase}

Moisture uptake caused by plasma damage can come from two sources. First, plasma bombardment removes the weakly bonded methyl groups creating dangling bonds that can absorb water by forming $\mathrm{Si}-\mathrm{OH}$ bonds. Second, the incorporated polar function groups such as $-\mathrm{NH}_{\mathrm{x}}$ can absorb moisture by forming hydrogen bonds [26]. To study the moisture effect on the dielectric constant, a heating stage was added to the Woollam Ellipsometer to monitor the refractive index during annealing. The dielectric constant can be directly related to the refractive index as $\varepsilon(\lambda)=n(\lambda)^{2}+k(\lambda)^{2}$, where $\varepsilon$ is the relative dielectric constant; $n$ is the real part of the refractive index; $k$ is the imaginary part of the refractive index (extinction factor) and $\lambda$ is the wavelength of the light source. The stage provided a clean and dry nitrogen environment to measure the refractive index during in-situ heating. Low $\mathrm{k}$ samples were separately treated by downstream plasmas of $600 \mathrm{eV}$ hybrid $\mathrm{He}, 50 \mathrm{eV}$ hybrid $\mathrm{NH}_{3}$, and $400 \mathrm{eV}$ hybrid Ar. After one hour of heating, their refractive indexes at $633 \mathrm{~nm}$ were all reduced (Fig. 10). The reduction was most significant for the $50 \mathrm{eV}$ hybrid $\mathrm{NH}_{3}$ treated sample with its refractive index being reduced from 1.44 to 1.36 , close to that of the pristine sample. This suggested that $\mathrm{k}$ was nearly fully recovered. The dielectric recovery for the 
higher energy $\mathrm{He}$ and Ar plasmas of $400 \mathrm{eV}$ or $600 \mathrm{eV}$, respectively was less complete, particularly for the $600 \mathrm{eV}$ plasma. As discussed already, energetic ions can alter Si-OSi backbone bonds, making the full recovery of the refractive index or the dielectric constant by heating difficult. Moisture removal was directly confirmed by monitoring the differential FTIR for low k samples after the $\mathrm{NH}_{3}$ plasma treatment (Fig. 11). With the temperature increasing from $100^{\circ} \mathrm{C}$ to $250^{\circ} \mathrm{C}$, water and $\mathrm{Si}-\mathrm{OH}$ between 3200 and $3600 \mathrm{~cm}^{-1}$ were found to decrease with corresponding increase in Si-O-Si between 950 and $1250 \mathrm{~cm}^{-1}$. This indicated that moisture was gradually removed as $\mathrm{Si}-\mathrm{OH}$ was condensed to form $\mathrm{Si}-\mathrm{O}-\mathrm{Si}$ bonds.

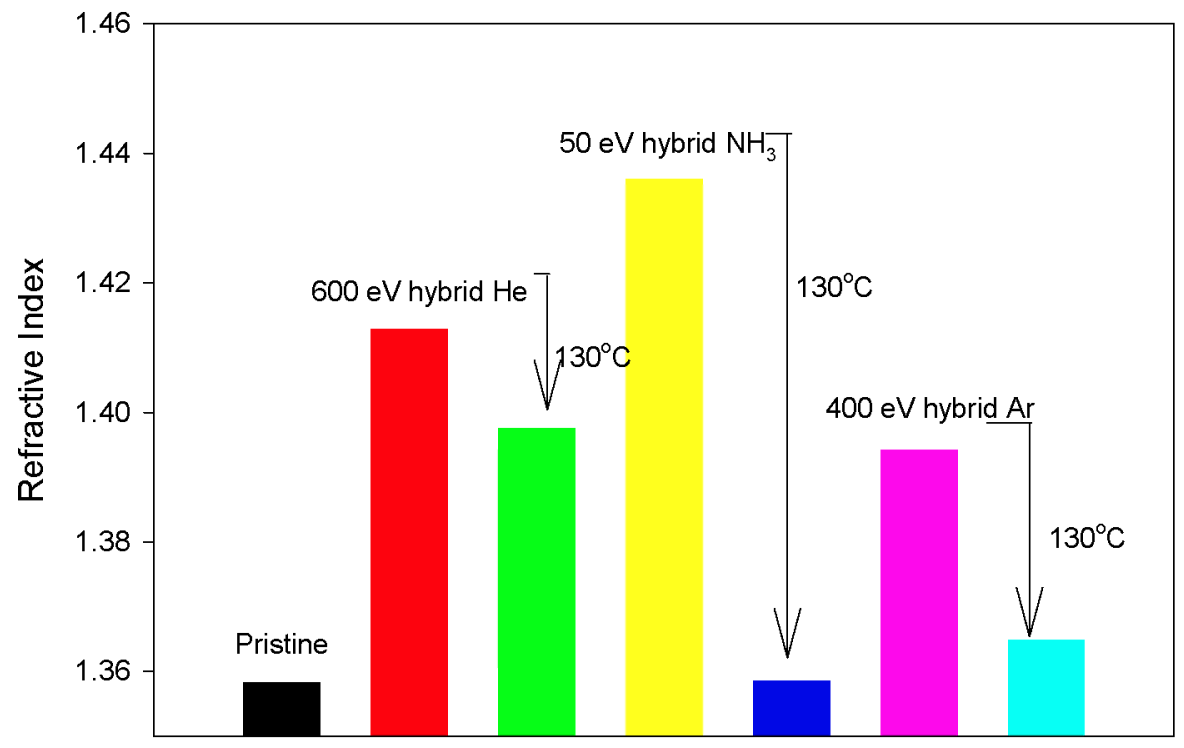

Figure 10. Recovery of the refractive index after plasma damage by annealing. Samples were treated by downstream hybrid plasmas of $600 \mathrm{eV}$ $\mathrm{He}, 50 \mathrm{eV} \mathrm{NH}$, and $400 \mathrm{eV} \mathrm{Ar}$ respectively at $1 \mathrm{mtorr}$ for $40 \mathrm{~min}$ and then annealed at $130^{\circ} \mathrm{C}$ for 1 hour. 


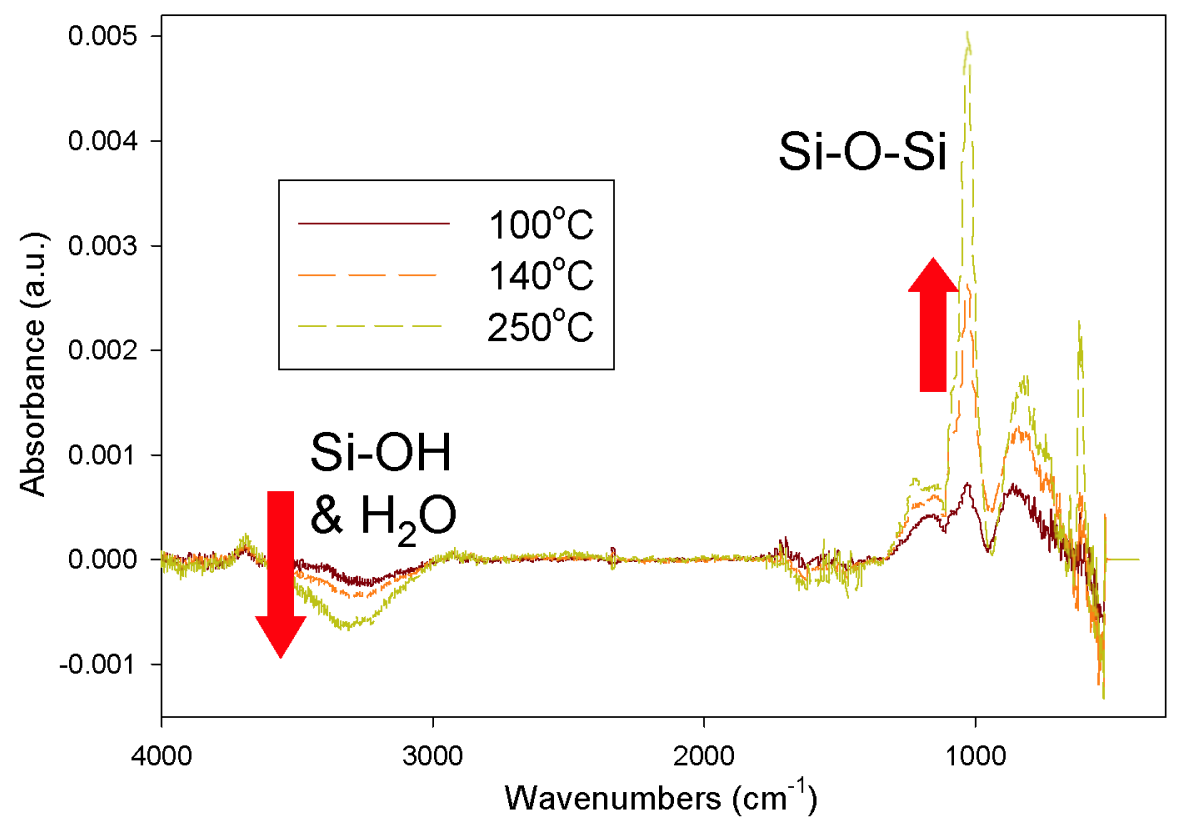

Figure 11. Differential FTIR spectra of low $\mathrm{k}$ films after annealing at $100^{\circ} \mathrm{C}, 140^{\circ} \mathrm{C}$ and $250^{\circ} \mathrm{C}$ for 1 hour respectively. Samples were damaged by $\mathrm{N}_{2} / \mathrm{H}_{2}$ plasma for $20 \mathrm{~min}$. in an Oxford RIE chamber.

The dielectric constant, a frequency-dependent and intrinsic material property, consists of three components: electronic, ionic and dipolar polarization [27]. A general expression is given as $\varepsilon=1+\Delta \varepsilon_{i}+\Delta \varepsilon_{e}+\Delta \varepsilon_{d}$ comprising of ionic, electronic and molecular dipole contributions. Specifically, a qualitative expression is given by the Clausius-Mossotti equation $\frac{\varepsilon-1}{\varepsilon+2}=\frac{\rho}{M} \times \frac{N_{A}}{3 \varepsilon_{0}}\left(\alpha_{i e}+\frac{p^{2}}{3 k T}\right)$, where $\varepsilon$ is the dielectric constant; $\rho$ is the density; $\mathrm{M}$ is the molecular weight; $\alpha_{i e}$ is the electronic and ionic polarizability and $\mathrm{p}$ is the dipole moment [28]. Quantum chemistry calculations based on the Gaussian ' 03 software were performed to investigate how plasma modification of low $\mathrm{k}$ materials affects its dipole moments and increase its dielectric constant. A detailed description of the calculation is beyond the scope of this paper, so here we summarize briefly the results. The calculation focused on the effect of moisture uptake in comparison to the effect of surface bonding changes. The moisture effect was evaluated by attaching directly the $\mathrm{H}_{2} \mathrm{O}$ molecule to the $\mathrm{Si}-\mathrm{OH}$ bond. To investigate the surface bonding effect, a variety of bonding configurations were studied, including replacing the $-\mathrm{CH}_{3}$ by $-\mathrm{OH},-\mathrm{NH}_{2}$, or $-\mathrm{O}$, or completely removing it from the surface. The results showed that the dipole moment induced by physisorbed water was at least 
one order-of-magnitude higher. Thus it should dominate the dielectric constant increase. This result is consistent with the experimental observation.

\section{CONCLUSIONS}

In summary, plasma damage of low $\mathrm{k}$ materials was found to be a complex phenomenon involving both chemical and physical effects. The physical effect is dominated by heavy molecular-weight plasmas at high energy/dose, which induce significant densification of the low $\mathrm{k}$ surface. The chemical effect is dominated by light molecular-weight plasmas at low energy/dose altering surface chemistry and composition. Study of the downstream plasma damage to blanket low $\mathrm{k}$ films indicated that ions played a more important role in causing plasma damage than the neutrals. Plasma damage will induce changes in bonding configurations, decreasing the $\mathrm{Si}-\mathrm{CH}_{3}$, cage and network structures while increasing the suboxide structure. The dielectric constant of CDO can increase up to $20 \%$ due to plasma damage and we attributed this to the removal of the methyl group making the low $\mathrm{k}$ surface hydrophilic. Annealing was generally effective in mitigating moisture uptake to restore the $\mathrm{k}$ value but the recovery was less complete for higher energy plasmas. Quantum chemistry calculation confirmed that physisorbed water in low $\mathrm{k}$ materials induces the largest increase of dipole moments in comparison with changes of surface bonding configurations, and is primarily responsible for the dielectric constant increase.

Acknowledgement - This work was supported by Intel Corporation. The authors would like to acknowledge Dr. Yangmin Sun at Texas Materials Institute for the XPS depth profile measurement and the use of the fabrication and characterization facilities in Microelectronic Research Center and the Center of Nano and Molecular Science and Technology at University of Texas at Austin.

\section{REFERENCES}

1. International Technology Roadmap for Semiconductors, Semiconductor Industry Association, 2006

2. M. Morgen, E. T. Ryan, J. H. Zhao, C. Hu, T. Cho and P. S. Ho, Annu. Rev. Mater. Sci. 30, 645$680(2000)$

3. K. Maex, M. R. Baklanov, D. Shamiryan, F. Iacopi, S. H. Brongersma and Z. S. Yanovitskaya, J. Appl. Phys 93, 8793 (2003)

4. D. Moore, R. Carter, H. Cui, P. Burke, P. McGrath, S. Q. Gu, D. Gidley and H. Peng, J. Vac. Sci. Technol. B 23, 332 (2005)

5. D. Shamiryan, M. R. Baklanov, S. Vanhaelemeersch and K. Maex, J. Vac. Sci. Technol. B 20, $1923(2002)$

6. F. Iacopi, M. Stucchi, O. Richard and K. Maex, Electrochemical and Solid-State Letters, 7, G79 (2004)

7. M. A. Worsley, S. F. Bent, N. C. M. Fuller, T. L. Tai, J. Doyle, M. Rothwell and T. Dalton, J. Appl. Phys 101, 013305 (2007)

8. J. J. Bao, H. L. Shi, J. J. Liu, H. Huang, P. S. Ho, M. D. Goodner, M. Moinpour and G. M. Kloster, Proc. of IITC, 147 (2007)

9. E. Kesters, Q. Le, W. Boullart, Q. Han, I. Berry, C. Waldfried, P. Mertens and M. Heyns, Cleaning Technology in Semiconductor Devices Manufacturing IX. ECS, 319 (2005) 
10. H. Cui, R. J. Carter, D. L. Moore, H. G. Peng, D. W. Gidley and P. A. Burke, J. Appl. Phys, 97, $113302(2005)$

11. H. Shi, J. Bao, J. Liu, H. Huang, P. S. Ho, M. D. Goodner, M. Moinpour, and G. M. Kloster, Mater. Res. Soc. Symp. Proc., 990, B03-12 (2007)

12. B. P. Gorman, R. A. Orozco-Teran, Z. Zhang, P. D. Matz, D. W. Mueller and R. F. Reidy, J. Vac. Sci. Technol. B 22, 1210 (2004)

13. Y. S. Mor, T. C. Chang, P. T. Liu, T. M. Tsai, C. W. Chen, S. T. Yan, C. J. Chu, W. F. Wu, F. M. Pan, Water Lur and S. M. Sze, J. Vac. Sci. Technol. B 20, 1210 (2004)

14. J. Liu, W. Kim, J. Bao, H. Shi, W. Baek and P. S. Ho, J. Vac. Sci. Technol. B 25, 1071 (2007)

15. J. Liu, Ph.D Dissertation, The University of Texas at Austin, 2006

16. P. Abramowitz, M. Kiene and P.S. Ho, Appl. Phys. Lett., 74, 3293 (1999)

17. J. Liu, J. Bao, M. Scharnberg, W. C. Kim, P. S. Ho and R. Laxman, J. Vac. Sci. Technol. A 23(4), $1107(2005)$

18. Gaussian online manual: http://www.gaussian.com $/ \mathrm{g}$ ur/g03mantop.htm

19. D. Briggs and M. P. Seah, Practical Surface Analysis, Vol 1, (Wiley \& Sons, 1990)

20. C. Y. Wang, J. Z. Zheng, Z. X. Shen, Y. Lin and A. T. S. Wee, Thin Solid Films, 397, 90 (2001)

21. G. Socrates, Infrared Characteristic Group Frequencies, $2^{\text {nd }}$ Edition (Wiley and Sons, 1998)

22. P. F. Fewster, Rep. Prog. Phys. 59, 1339 (1996)

23. Q. T. Le, M. Patz, H. Struyf, M. Baklanov, W. Boullart, S. Vanhaelemeersch, and K. Maex, Abs $140,205^{\text {th }}$ Meeting, The Electrochemical Society, Inc (2004)

24. T. C. Chang, Y. S.Mor, P. T. Liu, T. M. Tsai, C. W. Chen, Y. J. Mei, S. M. Sze, Thin Solid Films, 398-399, $632(2001)$

25. A. Grill and D. A. Neumayer, J. Appl. Phys. 94, 6697 (2003)

26. B. A. Morrow and I. A. Cody, J. Phys. Chem. 80, 1995 (1976)

27. J. Y. Kim, M. S. Hwang, Y. H. Kim, H. J. Kim and Y. Lee, J. Appl. Phys. 90, 2469 (2001)

28. M. A. Omar, Elementary Solid State Physics (Addison-Wesley, New York, 1975) 